\title{
PENGEMBANGAN STANDARDISASI PENGELOLAAN PARIWISATA ALAM DI KAWASAN RAWAN BENCANA KOTA PARIAMAN
}

\section{Standardization Development of Natural Tourism Management in the Pariaman City Disaster-Prone Areas}

\author{
Dandi Arianto Pelly ${ }^{\star}{ }^{\star}$, Nada Fauziah ${ }^{2}$, Salsabila² ${ }^{2}$ Maryadi Budi Wiyono ${ }^{1}$ \\ ${ }^{1}$ MPPDAS Geografi Universitas Gadjah Mada, Bulaksumur, Yogyakarta \\ ${ }^{2}$ Geografi Universitas Negeri Padang, Air Tawar Barat, Padang \\ *e-mail: dandi.pelly21@gmail.com
}

\begin{abstract}
Abstrak
Pengelolaan pariwisata pesisir di kota Pariaman harus didorong untuk menerapkan prinsip berkelanjutan sesuai Standar Nasional Indonesia (SNI) tentang pengelolaan pariwisata alam dan mitigas bencana. Penelitian ini bertujuan untuk mengetahui tingkat ancaman dan kesiapan infrastruktur kota Pariaman dalam menerapkan arahan pengembangan objek wisata pesisir berkelanjutan. Menganalisis arahan pengembangan destinasi objek pariwisata pesisir untuk masa yang akan datang dengan meningkatkan kebutuhan fasilitas wisata dan fasilitas atraksi wisata sebagai standar nasional. Metode penelitian ini menggunakan interpretasi citra resolusi tinggi untuk menentukan lokasi wisata dan Surveilapangan sebagai validasi. Hasil interpretasi citra dan pengamatan survei lapangan menunjukkan adanya 12 objek wisata di sepanjang area pesisir Pantai Gondoriah hingga Pantai Sanur yang secara keseluruhan berada pada zona tingkat bahaya tinggi. Hasil analisis arahan pengembangan destinasi objek pariwisata pesisir menunjukkan bahwa area kawasan wisata Pantai Gandoriah hingga Pantai Sanur belum memiliki sarana prasarana mitigasi bencana yang memadai, seperti peta bencana, rambu evakuasi dan bangunan shalter bencana.
\end{abstract}

Kata kunci:pariwisata pesisir, rawan bencana, standarisasi.

\begin{abstract}
Management of coastal tourism in the Pariaman city must be encouraged to apply sustainable principles in accordance with Indonesian National Standards (SNI) on natural tourism management and disaster mitigation. This study aims to determine the level of threat and readiness of the infrastructure of the Pariaman city in implementing direction for the development of sustainable coastal tourism objects. Analysing the direction of the development of coastal tourism destinations for the future by increasing the need for tourist facilities and tourist attraction facilities as a national standard. This research method uses the interpretation of high-resolution imagery to determine tourist sites and field surveys as validation. The results of image interpretation and field survey observations show that there are 12 attractions along the coastal areas of Gondoriah Beach to Sanur Beach as a whole are in a high hazard level zone. The results of the analysis of the direction of the development of coastal tourism object destinations indicate that the tourist area of The Gandoriah Beach to Sanur Beach does not yet have adequate disaster mitigation infrastructure such as disaster maps, evacuation signs and disaster shalter buildings.
\end{abstract}

Keywords: coastal tourism, disaster prone, standardization.

\section{PENDAHULUAN}

\subsection{Latar Belakang}

Indonesia merupakan negara kepulauan terbesar di dunia yang memiliki 17.504 pulau dengan luas perairan laut 5,8 juta $\mathrm{km}^{2}$ (Kementerian Kelautan dan Perikanan, 2016). Luas wilayah laut di Negara Indonesia melebihi dari daratan. Kekayaan laut yang dimiliki seperti ikan, udang, dan berbagai jenis hewan laut lainnya menjadikan Indonesia sebagai negara kepulauan yang memiliki kemewahan luar biasa dalam sektor kelautan (Allen, 2008; Nelson, Schlüter, \& Vance, 2018).

Aneka ragam ekosistem laut dan pesisir yang ada di Indonesia, antara lain berupa keindahan pantai berpasir untuk dinikmati. Selain itu, banyak terdapat gua, laguna, estuari, hutan mangrove, padang lamun, rumput laut, dan terumbu karang yang memiliki daya tarik tersendiri sebagai objek wisata (Djou, 2013). Ancaman potensi bencana kepesisiraan yang tinggi serta rentannya masyarakat berdampak pada pembangunan dan pendapatan ekonomi yang rendah baik dari pemerintah maupun masyarakat sehingga wilayah dengan daya tarik tinggi dan berpeluang besar untuk berkembang di wilayah pesisir menjadi rendah dan cenderung melambat.

Infrastruktur jalan, rel, jembatan, dan bangunan hancur akibat kejadian bencana di beberapa kota di Indonesia, seperti Banda Aceh, Padang, Nusa Tenggara Barat, Kota Palu dan Donggala, Distrik Sentani Papua dan wilayah 
pesisir lainnya menjadi landasan untuk pembangunan di Kota Pariaman bahwa wilayah dan masyarakat yang hidup di sana berada pada keadaan yang rentan becana. Setelah beberapa kejadian bencana yag melanda wilayah pesisir, kini Kota Pariaman menjadi tujuan wisata populer sehingga mengalami pembangunan yang sangat cepat, disebabkan oleh pengembangan pariwisata alamnya bahkan menjadi prioritas utama pembangunan namun wilayah ini tetap memiliki potensi yang sangat rentan terhadap bencana alam dan hidrometeorologi (Wijaya \& Furqan, 2018).

Potensi bencana alam yang terjadi di wilayah pesisir Kota Pariaman, yaitu gempa bumi, tsunami, banjir, kenaikan permukaan air laut, dan angin badai. Potensi bencana alam tersebut mengancam masyarakat yang tinggal di wilayah pesisir perkotaan, seperti di Pesisir Kota Pariaman dan berdampak buruk bagi ekosistem pesisir (Lin, 2019; Wijaya \& Furqan, 2018). Pengelolaan pariwisata pesisir di Kota Pariaman harus didorong untuk menerapkan prinsip berkelanjutan sesuai Standar Nasional Indonesia (SNI) tentang pengelolaan pariwisata alam dan mitigas bencana (Lukiawan, Setyoko, \& Suminto, 2018). Parameter penilaiannya mencakup tingkat kualitas pengelolaan, pelayanan pariwisata, produk pariwisata dan sarana prasarana penunjang mitigasi bencana di wilayah pariwisata.

SNI yang terkait dengan pariwisata ialah SNI 8013:2014 tentang pengelolaan pariwisata alam, pada SNI ini lebih fokus pada pengelolaan pariwisata alam pada kawasan hutan. Untuk penerapan SNI ini, dibutuhkan suatu penilaian, rancangan penilaian kesesuaian SNI 8013:2014 meliputi kelestarian ekosistem (termasuk spesies), kelestarian objek wisata, kelestarian sosial-budaya, kepuasan pengunjung, dan prinsip manfaat ekonomi.

Penilaian tersebut akan menjadi alat monitoring dalam rangka mendukung pembangunan sektor pariwisata alam yang ramah lingkungan. Tahap pengembangan dari SNI 8013:2014 diharapkan memiliki prinsip mitigasi bencana agar memberikan nilai tambah pada pariwisata pesisir di Kota Pariaman. Prinsip mitigasi bencana perlu dijalankan untuk mendukung sektor pariwisata tetap selamat saat kejadian bencana melanda. Pengelolaan pariwisata pesisir juga harus menerapkan SNI 8357:2017 tentang Desa dan Kelurahan Tangguh Bencana. Mengingat wilayah pesisir di dominasi oleh desa wisata dan masyarakat desa yang rentan terhadap bencana alam kepesisiran.

Pengelolaan pariwisata pesisir berkelanjutan yang berdasarkan pada kajian tentag resiko bencana alam tingkat yang lebih detail dari SNI 8182:2017 tentang 'Pedoman pengkajian risiko bencana tingkat nasional dan provinsi menjadi tingkat kota atau bahkan tingkat desa' akan sangat bermanfaat bagi pengembangan dan pengelolaan kawasan pariwisata di daerah rawan bencana. Dibutuhkan kajian multidisiplin ilmu tentang resiko bencana baik bencana alam, seperti gempa, banjir, longsor, perubahan iklim dengan pariwisata, dan bidang pengetahuan wisatawan yang lebih luas, khususnya perilaku wisatawan, pemasaran, dan pariwisata berkelanjutan.

Proses mitigasi bencana pada daerah pesisir juga sangat penting adanya. Pembangunan gedung shalter pada wilayah zona merah tsunami semestinya menjadi utama, pembekalan rambu petunjuk evakuasi juga harus terpenuhi pada daerah keramaian. Pengetahuan spasial wisatawan dan masyarakat lokal harus dimiliki pada setiap individu mengingat kejadian bencana datang tanpa diprediksi jenis dan kekuatannya. Pada objek wisata dengan keramaian, mitigasi bencana ini menjadi suatu hal yang harus diperhatikan oleh pemerintah dan memiliki standar dalam pelaksanaannya.

\subsection{Rumusan Masalah}

Rumusan masalah dalam penelitian ini adalah:

1. bagaimana tingkat ancaman dan kesiapan infrastruktur kota Pariaman dalam menerapkan arahan pengembangan objek wisata pesisir berbasis bencana;

2. bagaimana arahan pengembangan destinasi pariwisata pesisir untuk masa depan dengan meningkatkan kebutuhan fasilitas wisata dan fasilitas atraksi wisata berbasis bencana sebagai standar nasional.

\subsection{Tujuan}

Penelitian ini bertujuan untuk:

1. mengetahui tingkat ancaman dan kesiapan infrastruktur kota Pariaman dalam menerapkan arahan pengembangan objek wisata pesisir berbasis bencana;

2. menganalisis arahan pengembangan destinasi pariwisata pesisir untuk masa yang akan datang dengan meningkatkan kebutuhan fasilitas wisata dan fasilitas atraksi wisata berbasis bencana sebagai standar nasional

\section{TINJAUAN PUSTAKA}

Pariwisata dianggap sebagai layanan ekosistem bagi manusia. Keberadaannya bermanfaat bagi kehidupan dengan demikian, penting untuk membangun sistem sosial-ekologis di daerah yang berkelanjutan secara spasial terutama 
pulau-pulau kecil dan kawasan konservasi. Pesisir dan pulau-pulau kecil adalah tujuan yang paling banyak dikunjungi oleh wisatawan setiap tahun (Kurniawan, Adrianto, Bengen, \& Prasetyo, 2019).

Pariwisata merupakan salah satu sektor yang penting bagi daerah berkembang, juga menunjukkan tingkat pertumbuhan yang luar biasa di seluruh dunia. Selain itu, pariwisata sangat bervariasi menurut kinerja ekonomi dan sosial, dengan pendapatan yang besar pada sektor pariwisata pesisir. Bahkan pariwisata telah mampu mengubah komunitas nelayan tradisional menjadi pelaku pariwisata (Chen \& Chang, 2017). Pesisir dan pulau-pulau kecil sebagai sumber ekonomi dan pendapatan juga menjadi memiliki suatu potensi bencana yang menakutkan bagi masyarakat dan para wisatawan (Lin, 2019; Meilianda et al., 2019).

Menurut Undang-undang No. 24 Tahun 2007 tentang Penanggulangan Bencana, bencana merupakan peristiwa atau rangkaian peristiwa yang mengancam dan mengganggu kehidupan dan penghidupan masyarakat yang disebabkan baik oleh faktor alam dan atau faktor non-alam maupun faktor manusia sehingga mengakibatkan timbulnya korban manusia.

Menurut Badan Standardisasi Nasional (2016), Standar Nasional Indonesia (SNI) merupakan standar berupa dokumen tertulis yang berisi aturan, pedoman, atau karakteristik suatu barang dan/jasa atau proses dan metode yang berlaku umum dan digunakan secara berulang. Standardisasi secara umum merupakan rangkaian proses mulai dari pengembangan standar (pemrograman, perumusan, penetapan dan pemeliharaan standar) dan penerapan standar yang dilaksanakan secara tertib dan bekerja sama dengan para pemangku kepentingan (Hadiyanto, B.L, \& Adinegoro, 2018; Louhenapessy \& Febriansyah, 2018)

SNI merupakan standar yang berlaku secara nasional di Indonesia. SNI dirumuskan oleh Komite Teknis (dulu disebut sebagai Panitia Teknis) dan ditetapkan oleh BSN (BSN, 2017). Lembaga pemerintah yang memiliki tugas pokok mengembangkan dan membina kegiatan standardisasi di Indonesia adalah Badan
Standardisasi Nasional (BSN) (Peraturan Presiden Nomor 3 Tahun 2013). Dalam perkembangannya, kegiatan standardisasi di Indonesia dilaksanakan oleh semua pemangku kepentingan yaitu pemerintah, pelaku usaha, dan swasta.

\section{METODE PENELITIAN}

Penelitian ini berlokasi pada objek wisata Pantai Gandoriah hingga Pantai Sanur di wilayah pesisir Kota Pariaman, Provinsi Sumatera Barat (Gambar 2). Kota Pariaman merupakan kota dengan penghasilan utama daerahnya berasal dari sektor pariwisata, daerah ini terus mengalami perkembangan pariwisata di wilayah pesisir pantai (Khairiah, Hastini, \& Tou, 2019).

Data yang dibutuhkan dalam penelitian ini adalah data primer dan data sekunder. Data primer merupakan data yang di ambil langsung di lapangan berupa koordinat lokasi dan dokumentasi objek pariwisata serta untuk data validasi interpretasi citra satelit. Sementara data sekunder diperoleh dari interpretasi citra Google Earth (Gambar 1). Google Earth merupakan penyedia citra gratis dalam resolusi spasial tinggi yang dapat memberikan beberapa potensi untuk pemetaan penggunaan atau tutupan lahan secara regional dan akurat (Alivah, Setiawan, \& Sediyono, 2016).

Citra resolusi tinggi dari Google Earth dapat digunakan untuk memperoleh informasi tentang kondisi aktual pemanfaatan lahan yang dijadikan sebagai data analisis. Pengelolaan wilayah pesisir berbasis bencana adalah inisiatif pengelolaan data yang terdiri dari pengumpulan data, transfer data dan standar metadata dari nilai fokus yang berasal dari data lingkungan untuk dapat dimaksimalkan (Rumson, Hallett, \& Brewer, 2017). Untuk kebutuhan pengukuran data posisi koordinat dan validasi citra satelit maka dilakukan survei pengukuran lapangan objek-objek pariwisata di Kota Pariaman. 


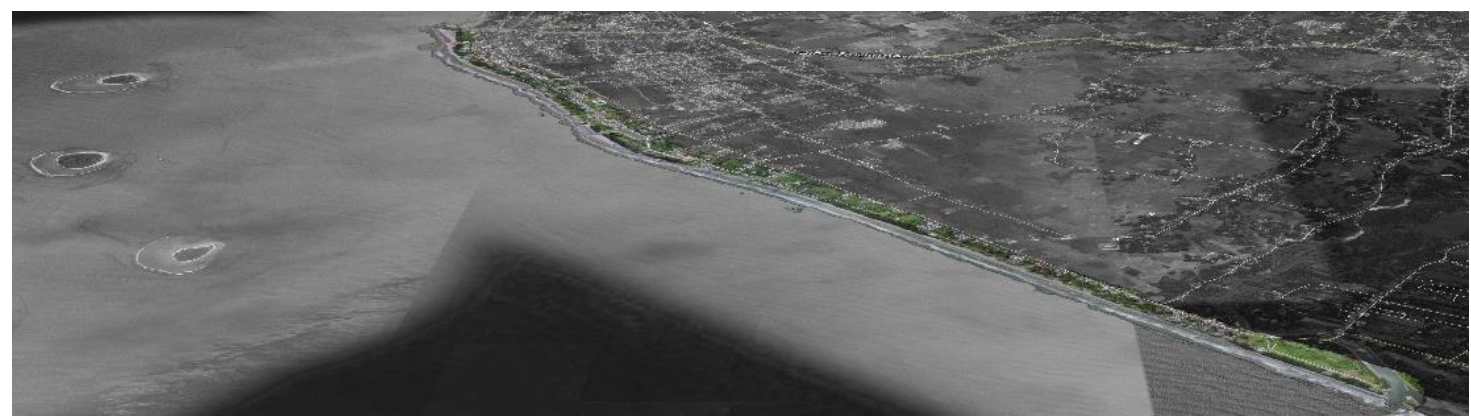

Gambar 1. Citra Google Earth Area Penelitian

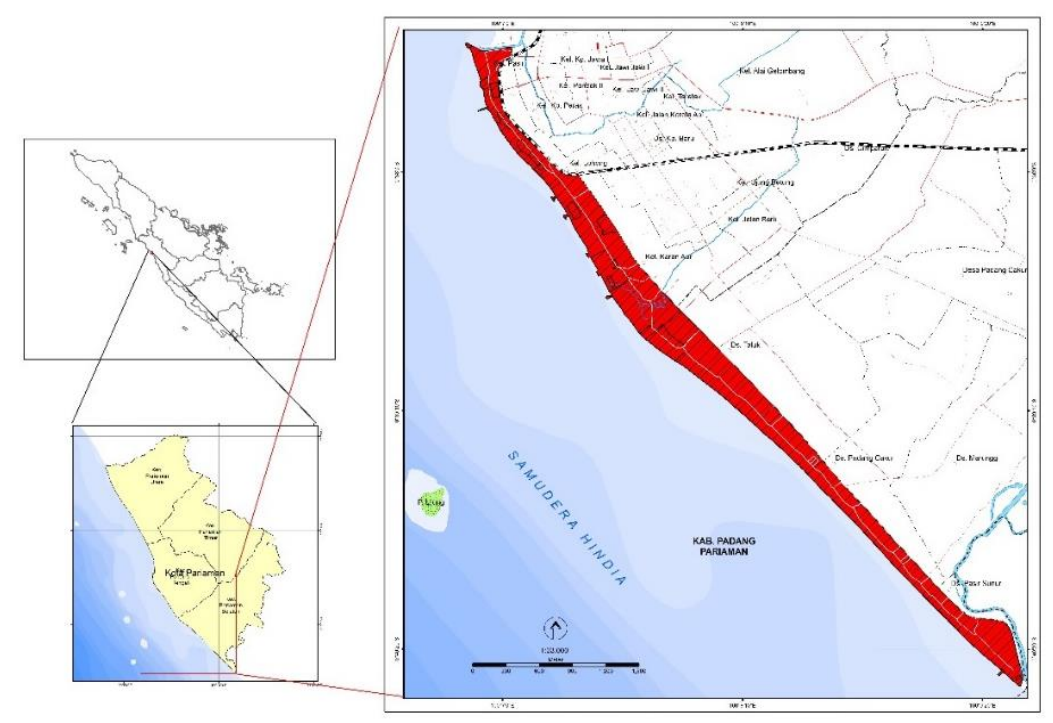

Gambar 2. Peta Lokasi Penelitian

Metode analisis pengolahan data dengan analisis spasial menggunakan Sistem Informasi Geografis (GIS) pada objek wisata kawasan pesisir Kota Pariaman. Serta metode survei dengan pengukuran di lapangan dalam menentukan validasi data lokasi agar memperoleh data objek wisata kawasan pesisir yang lebih valid.

\section{HASIL DAN PEMBAHASAN}

Wilayah pesisir barat Kota Pariaman merupakan Samudra Hindia yang memiliki resiko tinggi terjadinya bencana tsunami karena pada segmen patahan Mentawai di lautan lepas Kota Pariaman terdapat patahan-patahan aktif di zona subduksi. Pada zona ini setiap tahunnya selalu mengalami aktivitas gempa mulai dari guncangan ringan hingga kuat yang sewaktuwaktu dapat menimbulkan potensi bahaya yang lebih besar, yaitu tsunami. Wilayah pesisir kota yang berhadapan langsung dengan Samudra Hindia juga memiliki ancaman tinggi oleh bencana abrasi dan angin badai (Gambar 3).

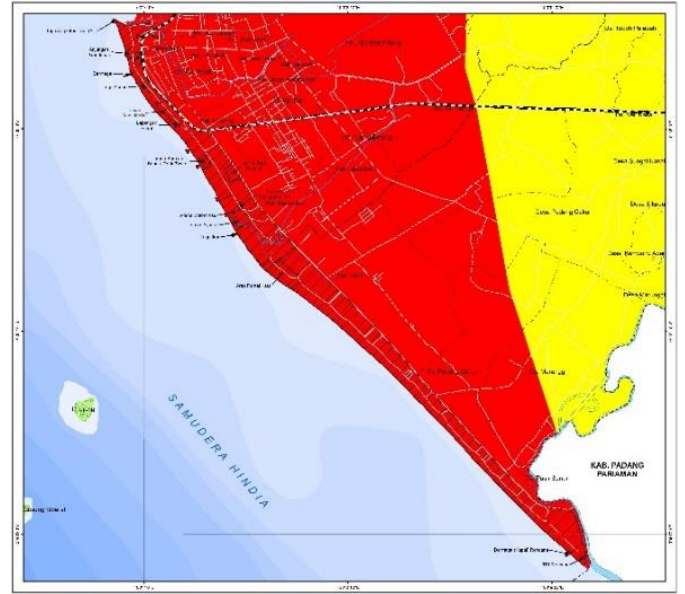

Gambar 3. Peta Rawan Bencana Kota Pariaman

Bencana gempa bumi yang terjadi dapat mengakibatkan kerusakan pada bangunan, sarana prasarana transportasi, yakni jalan jembatan, bendungan dan dapat menimbulkan tsunami bila terjadi pada kedalaman tertentu di wilayah laut. Berdasarkan hasil pemotretan citra satelit dapat diamati bahwa jarak garis pantai cukup dekat dengan bangunan objek wisata. Pada Gambar 4 tampak keadaan pantai padas 
saat pertunjukan wisata atau pada musim liburan. Oleh karena itu diperlukan adanya mitigasi struktural maupun non-struktural untuk menghindari maupun mencegah dampak buruk dari bencana yang akan membahayakan wisatawan maupun warga lokal.

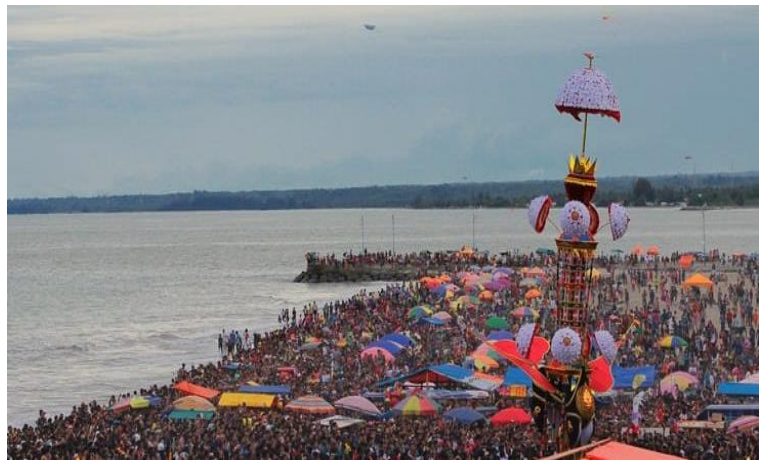

Gambar 4. Festival Tabuik (Sumber: Dokumentasi Warga)

Hasil interpretasi citra dan pengumpulan data primer untuk tujuan validasi di lapangan menunjukkan adanya 12 objek wisata di sepanjang area pesisir Pantai Gondoriah hingga Pantai Sanur, seperti ditunjukkan pada Tabel 1. Pembangunan objek wisata ini terfokus di Kecamatan Pariaman Tengah, Kota Pariaman (Gambar 5). Perkembangan dan pembangunan terus dilakukan hingga kini, bahkan untuk menyongsong acara kearifan lokal 'tabuik', pemerintah setempat melakukan pembangunan secara cepat dalam mempersiapkan perhelatan akbar kebudayaan festival pesta rakyat tersebut.

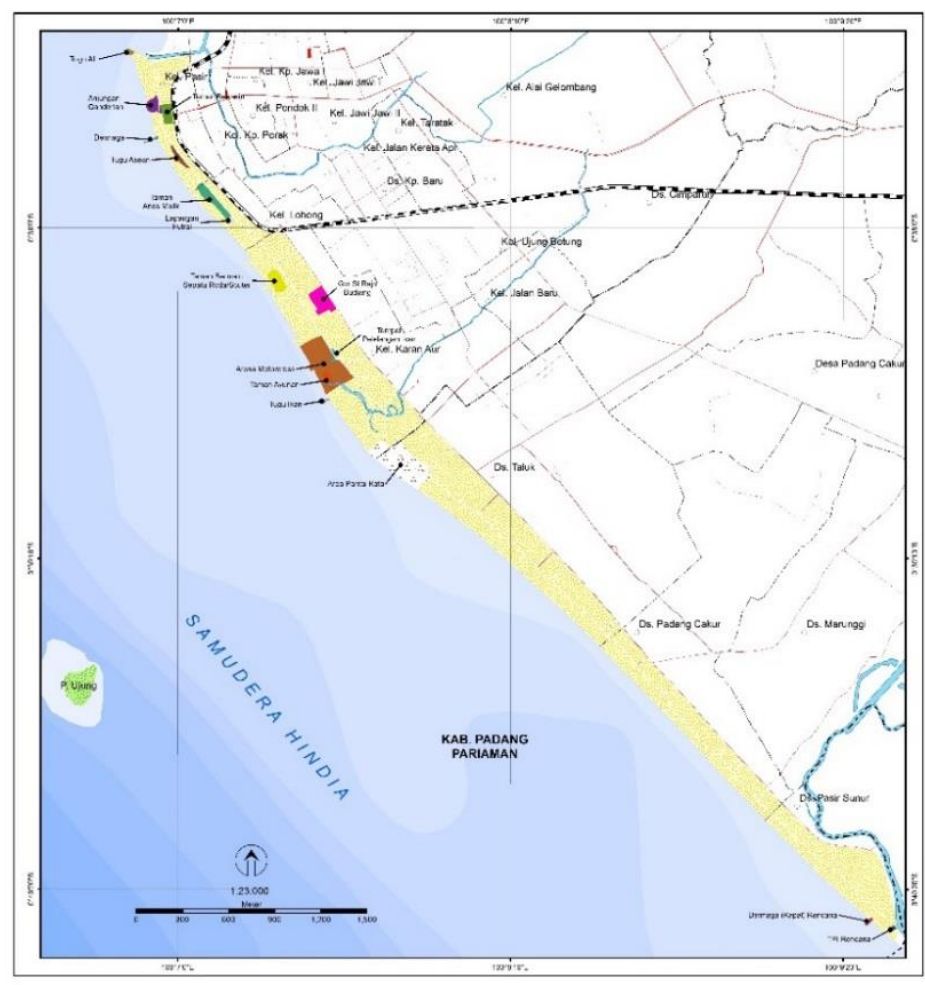

Gambar 5. Hasil Analisis Lokasi Objek Wisata Kota Pariaman

Rencana pembangunan sarana prasarana transportasi perairan untuk medukung program kepariwisataan terus dilakukan. Salah satunya melalui rencana pembangunan dermaga kapal untuk wisatawan menuju pulau-pulau kecil di lepas pantai Kota Pariaman. Berdasarkan hasil pengumpulan data primer di lapangan dan diskusi dengan pemangku kepentingan menyatakan bahwa dermaga tersebut akan dibangun segera di daerah Pantai Sanur, beserta Tempat Pelelangan Ikan (TPI) untuk nelayan tradisional yang melakukan aktivitas penangkapan ikan di area tersebut.

Rencana pembangunan dermaga di Pantai Sanur berlokasi di ujung perbatasan dengan wilayah Kabupaten Padang Pariaman, seperti ditunjukkan pada Gambar 6. Hal ini pun diharapkan dapat menjadi sarana bagi warga Kabupaten Padang Pariaman yang berdekatan dengan dermaga dan TPI dapat terbantu untuk aktivitas perekonomian. 


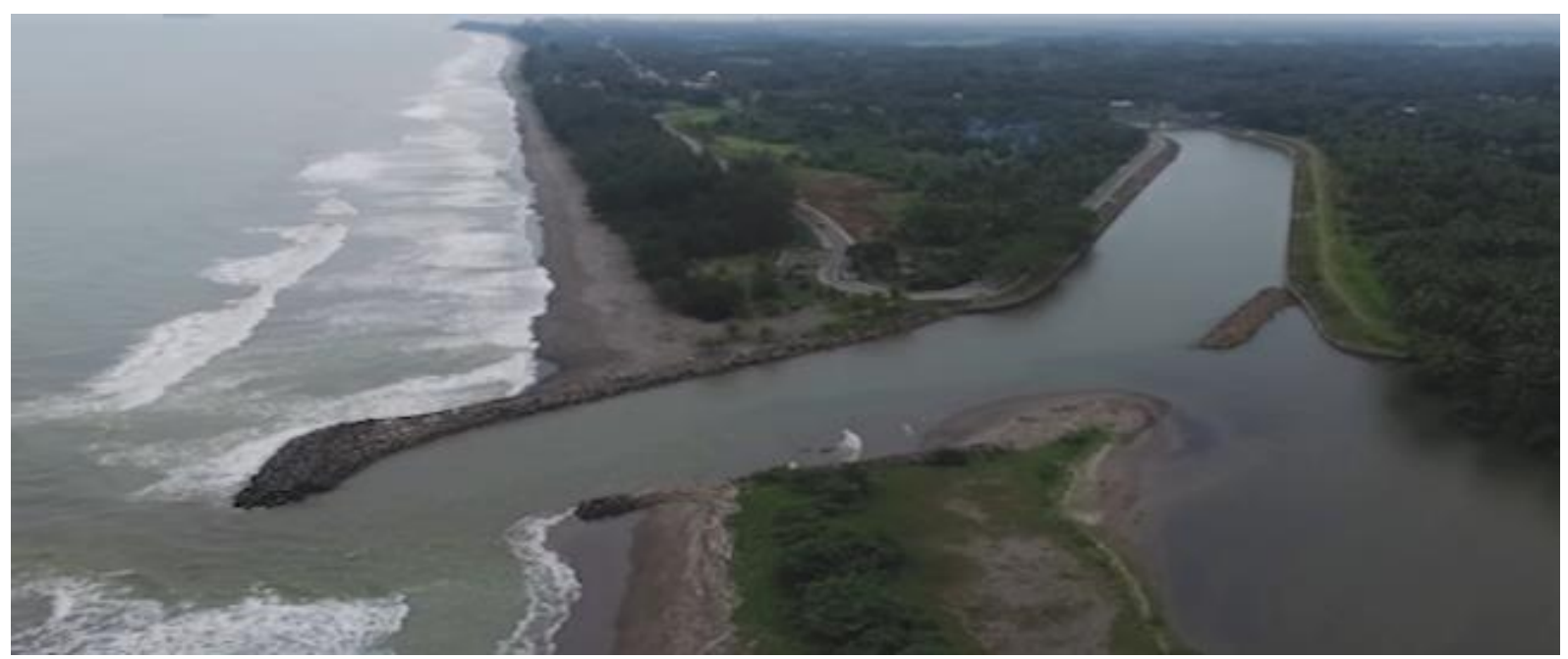

Gambar 6. Pantai Sanur (Sumber: Dinas PU Kota Pariaman 2019)

Tabel 1 Objek Wisata dan Sarana Wisata.

\begin{tabular}{lcl}
\hline \multicolumn{1}{c}{ Nama Objek } & Luas $\left(\mathbf{m}^{2}\right)$ & Keterangan \\
\hline Anjungan Gandoriah & 7485.51 & Objek Wisata \\
Taman Bermain & 8561.80 & Objek Wisata \\
Tugu AL & 1420.89 & Objek Wisata \\
Tugu Asean & 5564.96 & Objek Wisata \\
Taman Anas Malik & 13755.70 & Objek Wisata \\
Gor St Rajo Budjang & 17899.90 & Objek Wisata \\
Tugu Ikan & 1023.22 & Objek Wisata \\
Arena Motorcross & 56708.00 & Objek Wisata \\
Taman Ayunan & 4198.56 & Objek Wisata \\
Lapangan Futsal & 1861.29 & Objek Wisata \\
Area Pantai Kata & 64086.60 & Objek Wisata \\
Taman Bermain Sepatu Roda/Scuter & 10588.10 & Objek Wisata \\
Dermaga & 1048.49 & Sarana Wisata \\
Tempat Pelelangan Ikan & 1881.63 & Sarana Wisata \\
Dermaga (Kapal) Rencana & 1225.96 & Sarana Wisata \\
Tempat Pelelangan Ikan Rencana & 1161.49 & Sarana Wisata \\
\hline
\end{tabular}

Sumber: Hasil Analisis Lapangan di Atribut GIS 


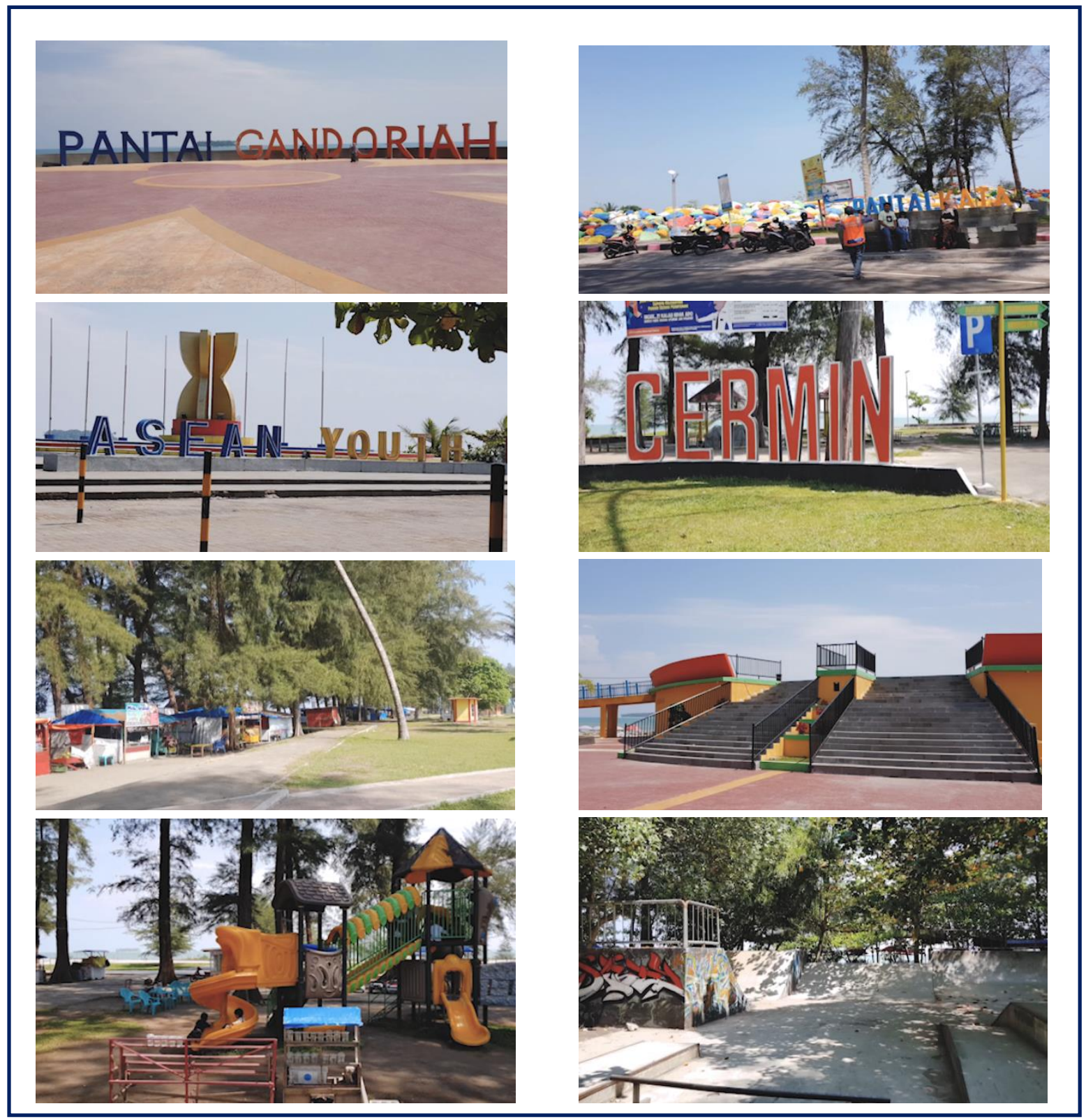

Gambar 7. Dokumentasi Lokasi Perkembangan Objek Wisata Pesisir Kota Pariaman

Hasil analisis arahan pengembangan destinasi objek pariwisata pesisir menunjukkan bahwa area kawasan wisata Pantai Gandoriah hingga Pantai Sanur belum memiliki sarana prasarana mitigasi bencana yang memadai, seperti peta bencana, rambu evakuasi dan bangunan shalter bencana, seperti tampak pada Gambar 7.

Pariwisata berbasis bencana adalah salah satu program yang signifikan dalam gerakan mitigasi dan kesadaran akan bencana oleh warga, pemerintah maupun wisatawan. Kegiatan yang dilakukan oleh para warga di kawasan rawan bencana dan para wisatawan dapat turut andil. Program ini mengindikasikan adanya kemungkinan kontribusi terhadap sektor industri pariwisata yang dapat memulihkan dan meningkatkan pendapatan ekonomi dengan menumbuhkan kesadaran akan bencana yang sewaktu waktu dapat hadir.

Pariwisata berbasis bencana memiliki nilai yang unik dan memiliki fungsi sebagai sarana pembelajaran dari masa lalu untuk menghindari kejadian atau bencana serupa di masa mendatang. Oleh karena itu, untuk pembangunan pariwisata berkelanjutan berbasis bencana pada masa yang akan datang dengan meningkatkan kebutuhan fasilitas wisata dan fasilitas atraksi wisata sebagai standar nasional, dibutuhkan adanya standarisasi pengelolaan 
beserta kelengkapan fasilitas pendukung keselamatan.

Standarisasi yang memberikan arahan pagi pemangku kepentingan dalam mengambil suatu langkah kebijakan dalam pembangunan lokasi wisata yang berada pada wilayah rawan terjadi bencana. Regulasi ini juga menjadi pedoman bagi swasta yang akan melakukan investasi di lokasi pembangunan pariwisata pesisir ini.

\section{KESIMPULAN}

Tahap pengembangan dari SNI 8013:2014 diharapkan memiliki prinsip mitigasi bencana agar memberikan nilai tambah pada pariwisata pesisir, seperti dipesisir Kota Pariaman. Prinsip mitigasi bencana perlu dijalankan untuk mendukung keberlangsungan sektor pariwisata saat kejadian bencana melanda. Hal ini dilakukan dengan cara mengetahui tingkat ancaman dan kesiapan infrastruktur pariwisata, seperti penerapan arah pengembangan objek wisata pesisir berbasis bencana di Kota Pariaman.. Di sepanjang area pesisir Pantai Gondoriah hingga Pantai Sanur terdapat 12 objek wisata yang memiliki fasilitas dan infrastruktur kepariwisataan. Daerah tersebut berbatasan langsung dengan Samudra Hindia yang memiliki resiko tinggi terjadinya bencana.

Arahan pengembangan destinasi pariwisata pesisir untuk masa yang akan datang di Kota Pariaman sangat penting untuk dilakukan. Selain untuk meningkatkan fasilitas wisata dan fasilitas atraksi wisata sebagai standar nasional, diperlukan pula standarisasi pengelolaan pariwisata pesisir beserta fasilitas pendukung keselamatan. Hal tersebut dikarenakan masih minimnnya sarana prasarana mitigasi bencana berupa peta bencana, rambu evakuasi dan bangunan shalter bencana di lokasi penelitian ini.

\section{UCAPAN TERIMA KASIH}

Penulis mengucapkan terima kasih yang sebesar-besarnya kepada rekan-rekan di MPPDAS Geografi Universitas Gadjah Mada atas dukungannya dalam memberi koreksi dan arahan. Rekan-rekan Jurusan Geografi Universitas Negeri Padang yang meluangkan waktu untuk berdiskusi. Terima kasih kepada Bapak Dr. Arie Yulfa M.Sc selaku Ketua Jurusan Geografi Universitas Negeri Padang atas saran dan masukan ilmu yang sangat bermanfaat sehingga artikel ini dapat tersusun dengan baik.

\section{DAFTAR PUSTAKA}

Undang-undang Republik Indonesia Nomor 24 Tahun 2007 tentang Penanggulangan Bencana.

Alivah, E. N., Setiawan, A., \& Sediyono, E. (2016). Penentuan Luas Lahan dengan Bantuan Google Earth. In P. Mulyono, V. E. Jaya, P. Nugroho, A. Yuriwin, \& O. Sitorus (Eds.), Prosiding Seminar Nasional 3 rd CGISE dan FIT ISI 2016. Yogyakarta: Departemen Teknik Geodesi, Fakultas Teknik Universitas Gadjah Mada.

Allen, G. R. (2008). Conservation hotspots of biodiversity and endemism for Indo-Pacific coral reef fishe. Annales Zoologici Fennici, 44(August), 303-313. https://doi.org/10.1002/aqc

Chen, C. L., \& Chang, Y. C. (2017). A transition beyond traditional fisheries: Taiwan's experience with developing fishing tourism. Marine Policy, 79(February), 84-91. https://doi.org/10.1016/j.marpol.2017.02.01 1

Djou, J. A. G. (2013). Pengembangan 24 Destinasi Wisata Bahari Kabupaten Ende. Jurnal Kawistara, 3(1). https://doi.org/10.22146/kawistara.3958

Hadiyanto, J., B.L, B., \& Adinegoro, H. (2018). Kebutuhan Standar Metode Uji, Bahan Acuan, Dan Kompetensi Sdm Berbasis Bioteknologi Di Sektor Agroindustri. Jurnal Standardisasi, 19(1), https://doi.org/10.31153/js.v19i1.420

Khairiah, H., Hastini, L. Y., \& Tou, H. J. (2019). Arahan pengembangan destinasi pariwisata pantai gandoriah kelurahan pasia kecamatan pariaman tengah kota pariaman. Jurnal Teknik Sipil Dan Perencanaan, 1(3), 1-19.

Kurniawan, F., Adrianto, L., Bengen, D. G., \& Prasetyo, L. B. (2019). The socialecological status of small islands: An evaluation of island tourism destination management in Indonesia. Tourism Management Perspectives, 31(April), 136144. https://doi.org/10.1016/j.tmp.2019.04.004

Lin, P.-S. S. (2019). Building resilience through ecosystem restoration and community participation: Post-disaster recovery in coastal island communities. International Journal of Disaster Risk Reduction, 39(March), 101249. https://doi.org/10.1016/j.ijdrr.2019.101249

Louhenapessy, B. B., \& Febriansyah, H. (2018). Standardisasi Industri Nasional Kapal Di Indonesia. Jurnal Standardisasi, 19(1), 11. 
https://doi.org/10.31153/js.v19i1.405

Lukiawan, R., Setyoko, A. T., \& Suminto, S. (2018). Kesiapan Pelaku Usaha Jasa Perjalanan Wisata Dalam Penerapan Standar Usaha Pariwisata. Jurnal Standardisasi, 107. https://doi.org/10.31153/js.v18i2.703

Meilianda, E., Pradhan, B., Syamsidik, Comfort, L. K., Alfian, D., Juanda, R., ... Munadi, K. (2019). Assessment of post-tsunami disaster land use/land cover change and potential impact of future sea-level rise to low-lying coastal areas: A case study of Banda Aceh coast of Indonesia. International Journal of Disaster Risk Reduction, 41(August), 101292. https://doi.org/10.1016/j.ijdrr.2019.101292

Nelson, K. M., Schlüter, A., \& Vance, C. (2018). Distributional preferences and donation behavior among marine resource users in Wakatobi, Indonesia. Ocean and Coastal Management, 162, 34-45. https://doi.org/10.1016/j.ocecoaman.2017.0 9.003

Rumson, A. G., Hallett, S. H., \& Brewer, T. R. (2017). Coastal risk adaptation: the potential role of accessible geospatial Big Data. Marine Policy, 83(May), 100-110. https://doi.org/10.1016/j.marpol.2017.05.03 2

Wijaya, N., \& Furqan, A. (2018). Coastal Tourism and Climate-Related Disasters in an Archipelago Country of Indonesia: Tourists' Perspective. Procedia Engineering, 212, 535-542.

https://doi.org/10.1016/j.proeng.2018.01.06 9 
